\title{
Estimates of Seismic Potential in the Marmara Sea Region from Block Models of Secular Deformation Constrained by Global Positioning System Measurements
}

\section{Citation}

Meade, Brendan J., Bradford H. Hager, Simon C. McClusky, Robert E. Reilinger, Semih Ergintav, Onur Lenk, Aykut Barka, and Haluk Ozener. 2002. "Estimates of Seismic Potential in the Marmara Sea Region from Block Models of Secular Deformation Constrained by Global Positioning System Measurements." Bulletin of the Seismological Society of America 92 (1) (February 1): 208-215. doi:10.1785/0120000837. http://dx.doi.org/10.1785/0120000837.

\section{Published Version}

doi:10.1785/0120000837

\section{Permanent link}

http://nrs.harvard.edu/urn-3:HUL.InstRepos:12497937

\section{Terms of Use}

This article was downloaded from Harvard University's DASH repository, and is made available under the terms and conditions applicable to Other Posted Material, as set forth at http:// nrs.harvard.edu/urn-3:HUL.InstRepos:dash.current.terms-of-use\#LAA

\section{Share Your Story}

The Harvard community has made this article openly available.

Please share how this access benefits you. Submit a story.

\section{Accessibility}




\title{
Estimates of Seismic Potential in the Marmara Sea Region from Block Models of Secular Deformation Constrained by Global Positioning System Measurements
}

\author{
by Brendan J. Meade, Bradford H. Hager, Simon C. McClusky, Robert E. Reilinger, \\ Semih Ergintav, Onur Lenk, Aykut Barka, and Haluk Özener
}

\begin{abstract}
We model the geodetically observed secular velocity field in northwestern Turkey with a block model that accounts for recoverable elastic-strain accumulation. The block model allows us to estimate internally consistent fault slip rates and locking depths. The northern strand of the North Anatolian fault zone (NAFZ) carries approximately four times as much right-lateral motion $(\sim 24 \mathrm{~mm} / \mathrm{yr})$ as does the southern strand. In the Marmara Sea region, the data show strain accumulation to be highly localized. We find that a straight fault geometry with a shallow locking depth of 6-7 km fits the observed Global Positioning System velocities better than does a stepped fault geometry that follows the northern and eastern edges of the sea. This shallow locking depth suggests that the moment release associated with an earthquake on these faults should be smaller, by a factor of 2.3, than previously inferred assuming a locking depth of $15 \mathrm{~km}$.
\end{abstract}

Online material: an updated version of velocity-field data.

\section{Introduction}

The presence of large urban and industrial centers near the North Anatolian fault zone (NAFZ) around the Marmara Sea makes the assessment of the potential for large earthquakes there critical. In this context, geophysical and geological research efforts have been undertaken to better understand seismic hazards in this vulnerable area (e.g., Schindler and Pfister, 1997). Included in these efforts were initiatives to use the Global Positioning System (GPS) to monitor surface deformation in the greater Marmara region (Straub et al., 1997; McClusky et al., 2000). In addition, controlled source seismic studies were conducted in the Marmara Sea to identify the submarine faults of the western NAFZ (e.g., Aksu et al., 2000; Okay et al., 2000). The extent to which this area is prone to large earthquakes is highlighted by the devastation wrought by the two large earthquakes in the region in 1999 (e.g., Barka, 1999; Toksöz et al., 1999).

The 1999 İzmit $\left(M_{\mathrm{w}} 7.4\right)$ and Düzce $\left(M_{\mathrm{w}} 7.1\right)$ earthquakes broke a $150-\mathrm{km}$-long segment of the northern branch of the North Anatolian fault. These two earthquakes were the latest in a series of $11 M_{\mathrm{w}}>6.7$ shocks during the last century that broke most of the NAFZ from the Karliova triple junction to the Aegean Sea, a distance of more than 1000 km (Ambraseys, 1970; Barka, 1999). The progression of earthquake activity to the east of the Marmara Sea has been modeled in terms of stress transfer and release (Stein et al., 1997; Nalbant et al., 1998). In these models the static stress field induced by each large coseismic shock is oriented such that nearby fault segments are promoted toward failure by an increase in their Coulomb failure stress. In western Anatolia, this series of events progressed to the Marmara Sea with the large shocks of 1999.

In addition to the recent pattern of large earthquakes in western Turkey, longer-term studies of seismicity have suggested that the Marmara Sea region might be particularly susceptible to the occurrence of a large earthquake. Toksöz et al. (1979) concluded that an approximately $300-\mathrm{km}-\mathrm{long}$ segment of the fault system in the Marmara area has not ruptured seismically since the early sixteenth century and characterized the unbroken segment as a seismic gap capable of producing large earthquakes. The 1999 earthquake sequence filled in only the eastern half of the seismic gap in the Marmara Sea area (Hubert-Ferrari et al., 2000; Parsons et al., 2000), leaving the central Marmara Sea as the largest potential seismic gap in the region.

Some measure of the potential for large earthquakes can be gleaned from an analysis of the secular velocity field. Areas with large velocity gradients can be interpreted as regions where earthquakes are likely eventually to relieve ac- 
cumulated strain. In this context, we examine the secular pattern of surface velocities recorded by GPS measurements. An updated version of the velocity field reported by McClusky et al. (2000) highlights the main tectonic elements of the region (Fig. 1). Velocity vectors in the south are dominated by large $(\sim 25 \mathrm{~mm} / \mathrm{yr})$ westward components and show the relative motion of Turkey with respect to Eurasia (McKenzie, 1972). The magnitude of the velocity vectors decreases rather regularly with latitude. The motion of the Anatolian microplate is well approximated by a counterclockwise rotation about a Euler pole that lies near the northern edge of the Sinai Peninsula (McClusky et al., 2000). Further, the area over which deformation is localized appears to broaden to the west, corresponding to the splitting of the NAFZ into northern and southern strands. Despite the large velocity gradients, we do not see discrete jumps in velocity across faults. Instead, we see zones of deformation around faults where the velocity gradually changes from one block to another, consistent with the pattern of strain accumulation that characterizes the interseismic period of the seismic cycle.

In order to analyze this velocity field we develop a block model of regional deformation. This approach incorporates secular velocity and fault geometry estimates, as well as the physical process of elastic-strain accumulation. With this model it is possible to detail the extent to which different faulting hypothesis are compatible with geodetic data, to estimate fault slip rates and locking depths, and to locate regions of anomalous strain accumulation. This allows us to test competing fault geometry models for the Marmara Sea region. Further, we consider the implications for seismic potential associated with the optimal locking depth of these fault segments in the context of historical earthquake activity.

\section{Block Modeling}

The variation of the displacement rate at the surface of the earth in plate boundary zones depends upon the timescale over which it is measured. Over geologic timescales, particularly in regions dominated by strike-slip tectonics, deformation is dominated by motions on faults-blocks of crust slide past each other with relatively little permanent internal deformation. The displacement on faults typically takes place during earthquakes; the resulting elastic strain in the upper crust is greatest near the fault and falls off with distance in a way that is well modeled by the strain field due to a dislocation in an elastic half-space (e.g., Savage and Burford, 1973; Reilinger et. al. 2000). During interseismic time intervals, such as the time spanned by the GPS measurements that we consider in this article, the displacement rate approaches the geologic rate far from faults but shows the effects of elastic-strain accumulation near faults.

The predicted GPS velocity field is sensitive to the assumed distribution of fault slip rates among faults and the distribution with depth and along strike on individual faults. The classic model relating geodetic velocities to fault slip rate is that by Savage and Burford (1973). This model calculates the surface displacement rate as a function of position for a straight, infinitely long strike-slip fault separating two blocks of crust, each represented as an infinite elastic quarter-space. Between earthquakes, the fault is assumed to be locked to a constant locking depth, $D$; below this depth, the fault is assumed to slip everywhere at the geologic rate, $v$. The surface displacements as a function of distance from the fault for such a model are sketched in Figure 2a. At the time of an earthquake, the locked portion of the fault at depth less than $D$ undergoes a uniform displacement, resulting in a concentration of elastic strain near the fault (Fig. 2b). If

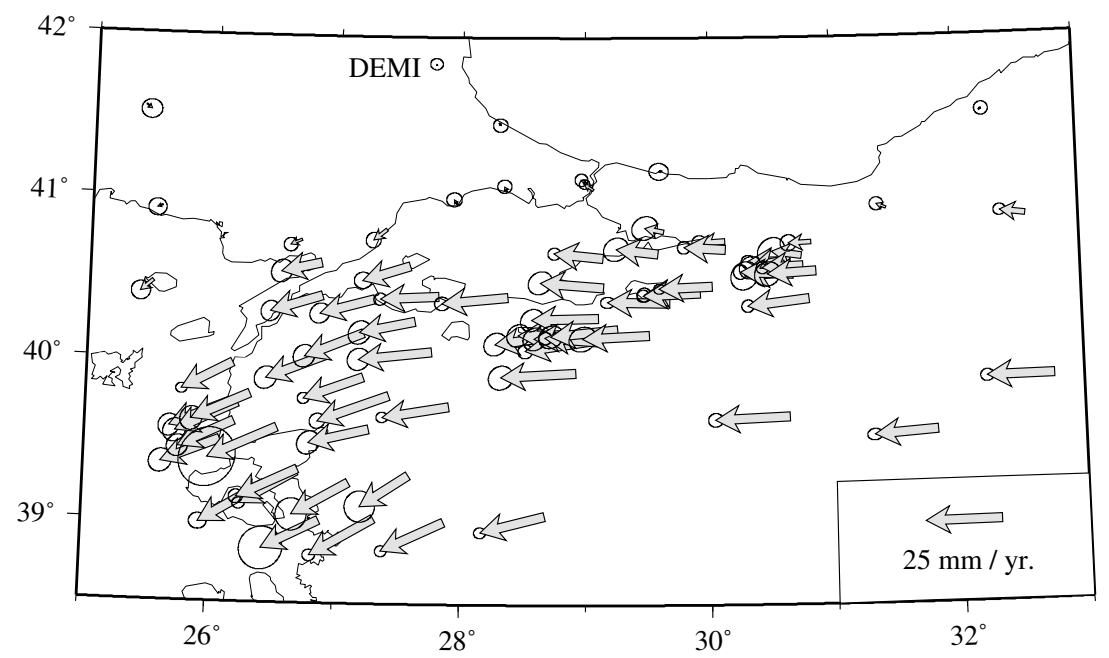

Figure 1. Updated GPS velocities near the Marmara Sea region, after McClusky et al. (2000). Velocities are shown relative to the site DEMI on the Eurasian Plate. Error ellipses represent $95 \%$ confidence intervals. (An updated version of the velocity-field that includes data collected through 1999 is available online at the SSA website.) 

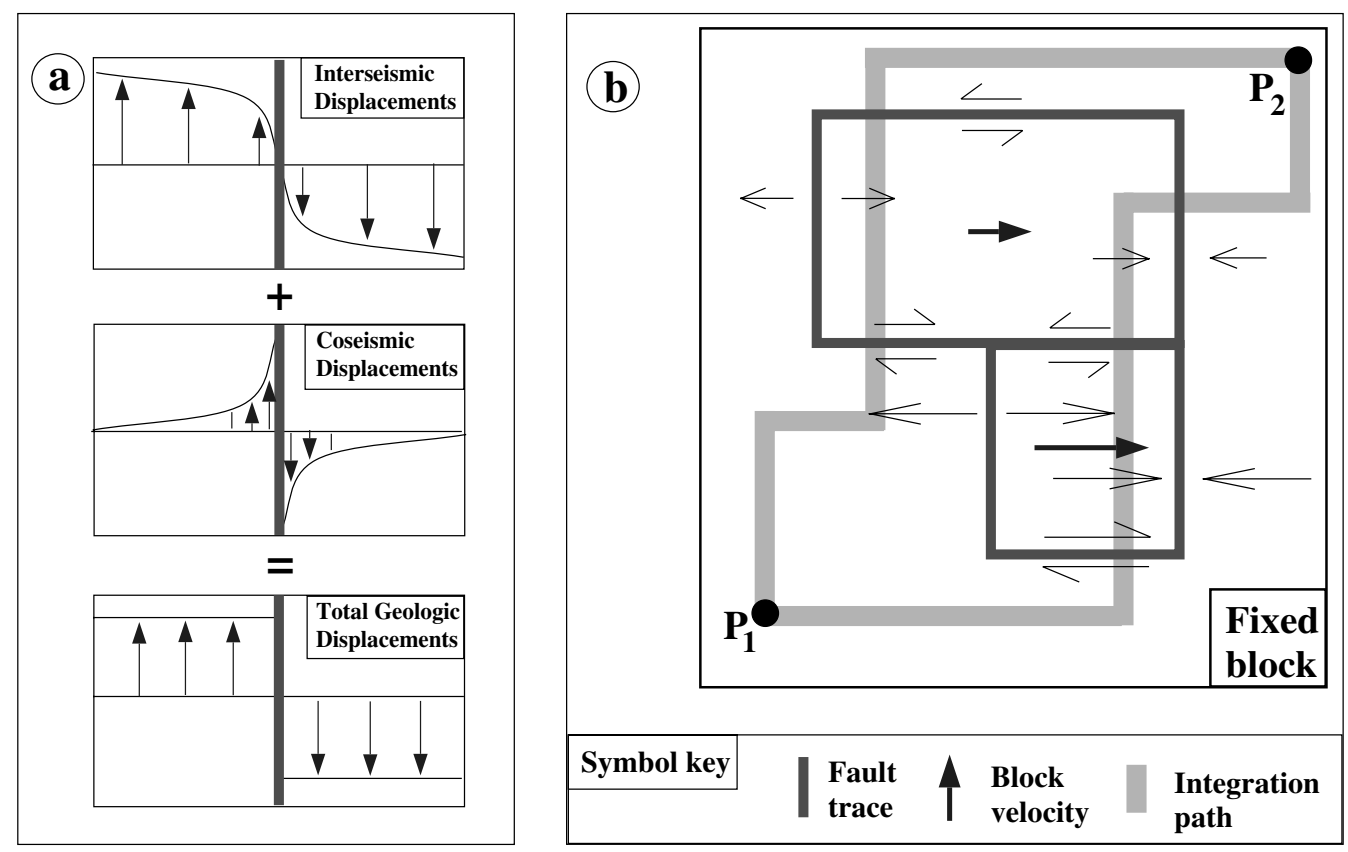

Figure 2. (a) Cartoon showing how geologic block motions are represented as the sum of coseismic and interseismic displacement fields. (b) Illustration of the basic principles of the block model. Two blocks are shown moving with respect to a third fixed block. The large arrows indicate the magnitude and direction of each block's motion. The small arrows give the sense of relative motion across the fault traces. The thick light gray lines indicate possible integration paths. Summing the components of slip along any path from $\mathrm{P}_{1}$ to $\mathrm{P}_{2}$ yields the same total.

the rate of earthquake occurrence is such that the long-term rate of displacement on the shallow, seismogenic segment of the fault matches the geologic rate, then there is negligible net elastic-strain accumulation, and the total geologic displacement rate (Fig. 2a) is identical to the sum of the interseismic displacement rate plus the average coseismic displacement rate. Because of this identity, the interseismic displacement field can also be calculated by subtracting the average rate of coseismic displacement, on a fault with depth less than $D$, from the geologic rate of motion between the two crustal blocks. This approach avoids numerical problems associated with calculating the displacements from dislocations with infinite depth extent.

Of course, Earth's rheological structure is more complicated than that of an elastic half-space, and processes including creep on faults at rates that vary as a function of position and time, as well as viscoelastic relaxation at depth, certainly take place. Because models that account for these processes show that it is difficult to discriminate between them (e.g., Savage and Lisowski, 1998), we address here only the effects of viscoelastic relaxation. Consider a model with an elastic layer of thickness $D$ overlying a Maxwell viscoelastic half-space with characteristic relaxation time $\tau=\eta / \mu$, where $\eta$ is the viscosity and $\mu$ is the shear modulus. Assume that the model is loaded with periodic earthquakes with characteristic repeat time, $T$, and displacement, $v T$. For ratios of $\tau / T$ greater than 0.5 , there is little variation in sur- face velocities through the earthquake cycle, with the surface velocities closely approximating those of the classic model (e.g., Savage and Lisowski, 1998). If $\tau / T$ is less than 0.2, then there are significant variations such that late in the earthquake cycle, the velocity gradient over the fault is spread out-suggestive of a large value of $D$ in the classic model.

As we show subsequently, the observed interseismic velocity gradients late in the earthquake cycle near the major faults in the Marmara Sea region are steep, requiring a locking depth shallower than or comparable to the observed rupture depths of the İzmit earthquake. It appears that the relaxation time in this region is long enough that the classic model provides an adequate mathematical representation of the velocity field late in the seismic cycle. Because there are multiple faults of variable strike and slip rate, we must extend the classic model. We calculate the effects of not a single, infinitely long fault, but of a network of finite faults of variable orientation that intersect, leading to changes in geologic displacement rates along them.

In the model we develop in this article, we divide the region into a number of blocks. Each fault segment makes up part of the boundary between two adjacent blocks (e.g., Souter, 1998; McClusky et al., 2001). The slip rate components on each fault segment are determined in an internally consistent manner by the projection of the relevant relative block velocity vector onto the fault plane (Fig. 2b). 
As in the classic Savage and Burford (1973) model, we assume that there is negligible temporal variation in the interseismic velocity, as would be the case if the viscoelastic relaxation time were greater than half the characteristic time between earthquakes. As in Figure 2a, we calculate the effects of elastic-strain accumulation, assuming that the faults are dislocations in an elastic half-space (Okada, 1985) with a Poisson's ratio of 0.25 . This allows us to model analytically the surface deformation due to an arbitrarily oriented dislocation in a Cartesian elastic half-space. We are not aware of similar closed form results for spherical bodies. We project the curved surface of our study area onto a plane using a Lambert conic conformal projection (Wessel and Smith, 1991).

Our model implicitly enforces a path integral constraint on both the secular and geologic velocity fields. This constraint insures that the relative velocity between any two points is not a function of the path connecting these two points (Fig. 2b). At fault intersections this is analogous to Kirchoff's current rule, with the components of fault slip substituted for current and faults playing the role of current paths. Our block model is consistent with this constraint over geologic timescales and assumes that locking depths are the same for all three components of the dislocation vector, differentiating it from previous block models (e.g., Matsu'ura et al., 1986; Bennett et al., 1996).

On a plane, the velocity, $\mathbf{v}$, of a point, $\mathrm{p}$, on an undeformed block, $b$, can be represented by a rotation of the block about some point, $\mathbf{v}_{\mathrm{p}}=\omega_{\mathrm{b}} \times\left(\mathbf{x}_{\mathrm{p}}-\mathbf{x}_{\omega}\right)=\omega_{\mathrm{b}} \times \mathbf{x}_{\mathrm{p}}+\mathbf{v}_{\mathrm{o}}$, where $\mathbf{x}_{\mathrm{p}}$ gives the coordinates of the point, $\mathrm{p}, \mathbf{x}_{\omega}$ gives the coordinates of the rotation axis or Euler pole, $\omega_{\mathrm{b}}$ is the block rotation vector, and $\mathbf{v}_{\mathrm{o}}=-\omega_{\mathrm{b}} \times \mathbf{x}_{\omega}$ is the translation of the origin due to rotation about $\mathbf{x}_{\omega}$. This decomposition shows that the rate of rotation about the Euler pole is the same as the rate of rotation about the origin and that the location of the unknown Euler pole can be replaced by the velocity at the origin, linearizing the problem. Thus, for the motion of a block in two dimensions, we have three degrees of freedom. For a collection of points on several blocks, we have a linear system of equations that can be solved for the block-motion parameters, $\mathbf{v}_{\mathrm{o}}$ and $\omega_{\mathrm{b}}$. While this theory is sufficient to study kinematics over geologic timescales, the ten-year timescale over which GPS observations have been acquired requires us to consider the mechanics of a deformed block. The strain accumulation due to a locked fault bounding two blocks affects not only those two blocks, but also propagates across all block boundaries. In the context of our block model, slip rates are the projection of relative block motions onto the fault-plane geometry. We assume vertical faults, with no vertical motion along fault surfaces. This leaves only strike-slip and tensile components to be considered. We still have a linear system of equations, $(\mathbf{A}-\mathbf{G D}) \mathbf{b}=\mathbf{v}$, for the deformed block case. Here $\mathbf{A}$ is a block assignment matrix, $\mathbf{G}$ relates block motions to components of slip on the bounding fault planes, $\mathbf{D}$ gives the partial derivatives of the elastic dislocation equa- tions, $\mathbf{b}$ is a vector of block-motion parameters, and $\mathbf{v}$ is a vector of the predicted velocities. As block motions are not, in general, known, we seek to estimate them by minimizing the weighted, correlated, squared residuals $\left(\chi^{2}\right)$ by differentiation, $\partial_{\mathbf{b}} \mathbf{r}(\mathbf{b}) \mathbf{C}^{-1} \mathbf{r}(\mathbf{b})=0$, where $\mathbf{r}$ is the residual velocity vector and $\mathbf{C}$ is the partial data covariance matrix.

Although we have thus far discussed only the linear effects of varying the slip rate on the surface deformation field, we should also consider other parameters. These are the locking depth of the fault and possible variations in material properties. Addressing the depth to which these faults appear to be locked has direct implications for seismic hazard assessment.

\section{Fault Geometry, Slip Rates, Seismic Gaps, and the Seismic Cycle}

The NAFZ has a single rather well defined trace throughout most of northern Turkey. Estimates of the relative motion across the fault zone have varied widely. Seismic estimates have ranged up to $31 \mathrm{~mm} / \mathrm{yr}$ (Jackson and McKenzie, 1984), whereas geologic estimates have been as low as 5-8 $\mathrm{mm} / \mathrm{yr}$ (Barka and Kadinsky-Cade, 1988). To the west of the Modurnu valley, the NAFZ splits into northern and southern strands. The southern NAFZ has two main strands (Straub et al., 1997). One of these strands runs just along the southern edge of the Marmara Sea and then to the Aegean through the Biga peninsula. The other strand lies approximately $50 \mathrm{~km}$ to the south, exits the mainland, and runs toward the island of Lesbos. While both of these strands have a history of generating large earthquakes (Ambraseys and Jackson, 2000), they prove to be so close together, and with such little relative motion across them, that it is difficult to distinguish the effects on the GPS velocity field of each individually. In this article, we treat the southern NAFZ as a single strand.

To the north, where there is more slip, questions of the geometry of active faulting are of paramount import and ambiguous resolution. Much of the difficulty in discerning the exact nature of faulting in this region is because most of the active traces are submarine. Despite this obvious limitation, several working hypotheses of the pattern of neotectonic deformation have been proposed. Based on seismic reflection data, Okay et al. (2000) suggested that the motion of a small block characterizes the northeast corner of the Marmara Sea. Aksu et al. (2000) used seismic reflection and bathymetric data to suggest that a single fault running east to west from İzmit Bay toward Golcuk is the active trace in recent times. Grossly, the difference between these two is that one model has fault segments running straight through the Marmara, whereas the other has them stepping northward toward the northern edge of the sea. While the marine environment prohibits the acquisition of GPS data there, the GPS data that are available nearby supply information with which to explore the implications of these models.

In differentiating between the straight and stepped fault 
models, we simplify the stepped model by considering only the deformation associated with the northern boundary of this block system. This geometry is comparable to that used by Hubert-Ferrari et al. (2000) in their assessment of seismic hazard. Given the diffuse nature of elastic-strain accumulation, the motions of many small blocks where there is so little data cannot be resolved. The difference in the geometry of these two hypotheses can be extended to the third dimension by also considering an optimal apparent locking depth for this region.

\section{Interpreting the Secular Velocity Field in Western Turkey}

We use the observed horizontal GPS velocities from the update of McClusky et al. (2000) (Fig. 1) to estimate block motions. A local reference frame is realized by minimizing the observed velocities at six sites north of the NAFZ. The relative velocities are inverted to estimate the three blockmotion parameters for each of the two blocks that are allowed to move. We estimate the set of block motions that gives a model velocity field that is most similar to the geodetic data in a least-squares sense. The difference between the observed and model velocities allows us to assess how appropriate our model might be (Fig. 3). Most of the residual velocities are quite small; the component-wise mean residual magnitude is about $1.2 \mathrm{~mm} / \mathrm{yr}$. The residuals shown are those associated with our preferred model, which incorporates the straight style fault geometry in the Marmara Sea and optimal elastic locking depths.

We use variations in elastic locking depth to explore the extent to which strain is localized along a fault zone. As locking depth is made shallower, the velocity variation across a given fault occurs across a narrower zone. If station velocities near a fault show a relatively rapid velocity gradient, this indicates a relatively shallow locking depth in the elastic dislocation model. We utilize two locking depths in our optimal model: a regional locking depth and a locking depth for the system of faults in the Marmara Sea region. The locking depths are determined by a three-step approach. First, we estimate the regional locking depth for all faults. We then fix all faults, other than those in the Marmara, at the regional locking depth and estimate the local locking depth for the Marmara faults. Finally, we estimate the regional locking depth again with the depth of the Marmara faults fixed and find it to be $17 \mathrm{~km}$.

To find which of the two Marmara fault geometry hypotheses best fits the GPS data, we carry out experiments

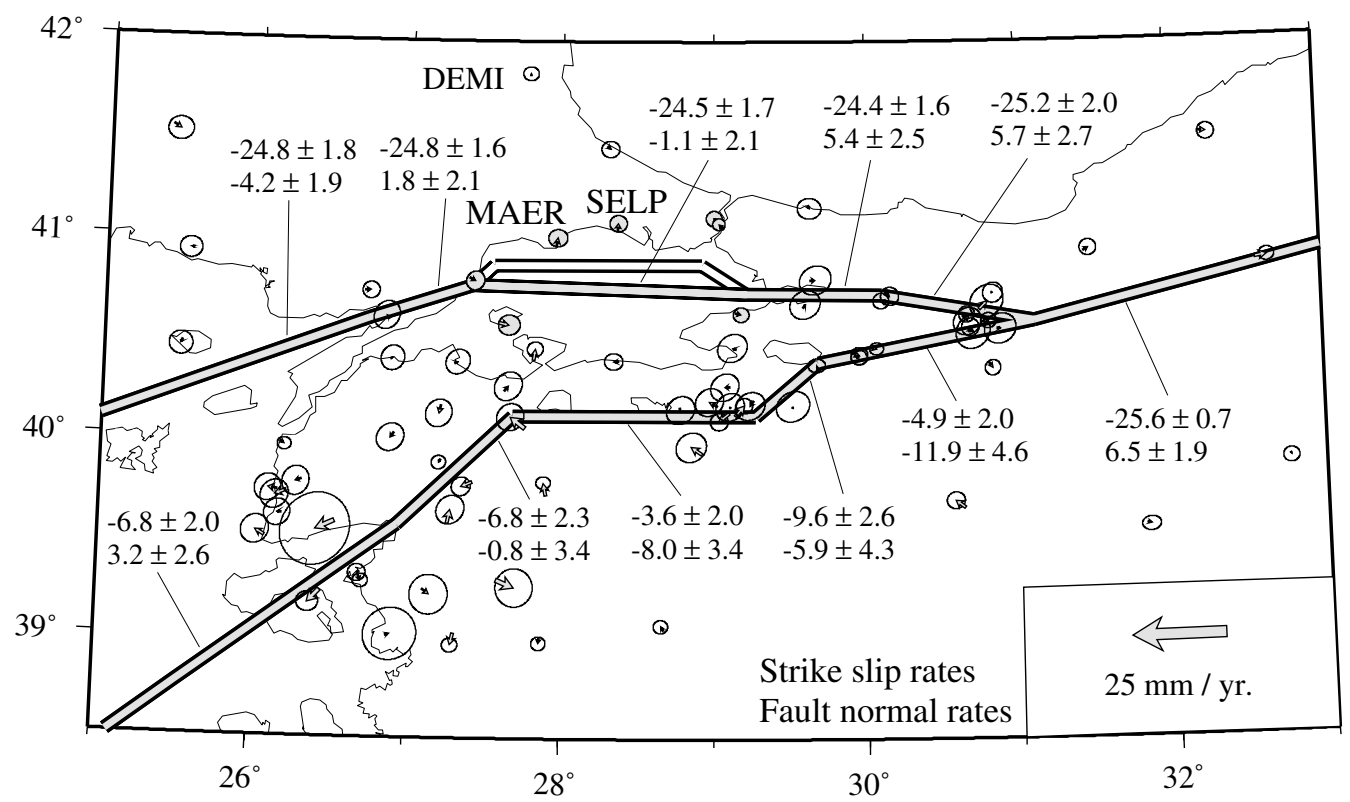

Figure 3. The residual (observed - model) velocity field is shown relative to DEMI. Most of the velocity vectors fit within the estimated 95\% confidence intervals for the observations. Stations with shaded error ellipses are those that contribute to the local chisquare value used to estimate the geometry and locking depth of the Marmara Sea faults. The seven sites with shaded ellipses are, from west to east, YENB, MISL, MAER, SELP, ITAY, IKAN, and CINA. The solid lines show the preferred fault model. The dashed line in the Marmara Sea shows that alternate stepped geometry. Slip rate estimates and their one-sigma uncertainty estimates associated with our preferred shown as pairs. The upper values are strike-slip rates, with negative values indicating right-lateral motion; the lower values are the fault-normal motion, with negative values indicating opening. The northern strand of the NAFZ carries approximately 4 times as much right-lateral motion as does the southern strand. Variations in slip rate between adjacent fault segments reflect the sensitivity of this calculation to fault geometry and block rotation rate. 
with local locking depths for both cases. This approach allows us to see if one style of fault geometry is preferred or if there are trade-offs between locking depth and fault geometry that preclude us from reaching any such conclusion. In order to highlight the sensitivity of nearby sites to the distribution of strain near these fault segments, we calculate a local chi-square $\left(\chi^{2}\right)$ (sum of weighted squared residuals) based on the seven sites shown with gray observed-error ellipses in Figure 3. When locked to a depth of $17 \mathrm{~km}$, both the fault geometry models generate eastward residual velocities outside of their $95 \%$ confidence ellipses for the two sites (MAER and SELP) that are closest to the northern edge of the Marmara. We find that both the stepped and straight models have optimal apparent locking depths substantially less than the global average (Fig. 4). For the straight style geometry we find the local chi-square value approximately equal to 30 at a depth of $6.5 \mathrm{~km}$, whereas the minimum chisquare value for the stepped geometry is about $50 \%$ greater (Fig. 4). The straight style fault geometry is preferable as the local chi-square value has a significantly lower minimum and provides a better solution than does the stepped geometry for most reasonable locking depth values. Our preferred model incorporates the straight style fault geometry in the Marmara Sea, a regional locking depth of $17 \mathrm{~km}$, and a local Marmara locking depth of 6-7 km.

We calculate confidence intervals on estimates for the locking depth of the Marmara Sea fault by Monte Carlo simulations. To do this we estimate the fault locking depth with different realizations of velocities at the sites used in the local chi-square calculation. Each velocity component is perturbed from its observed value by picking a random number from a Guassian distribution and normalizing the deviation by the estimated variance of the observable. The uncertainty in the determination of the local reference frame is propagated through these calculations. For our preferred fault geometry we find the best locking depth and one-sigma uncertainty estimate is $6.5 \pm 1.1 \mathrm{~km}$ at the $95 \%$ confidence level (Fig. 4).

The slip rates associated with this model (Fig. 3) stand in support of the idea that the northern strand of the NAFZ carries more right-lateral motion than does the southern strand. In fact, the northern strand appears to support nearly as much slip west of the fault-trace bifurcation as the NAF proper does to the east. Indeed, the slip rates in the Marmara range up to $24.3 \pm 1.6 \mathrm{~mm} / \mathrm{yr}$ of right-lateral motion with a small amount of opening. Figure 4 also shows the slip rate on the Marmara Sea fault as a function of different locking depths. Over the range of locking depths from 0 to $15 \mathrm{~km}$, the change in the strike-slip rate does not vary outside of the one-sigma uncertainty estimates.

\section{Discussion}

The small magnitudes seen in the residual velocity field suggest that our block model may be appropriate; it is compatible with observed secular velocities, fault geometry estimates, geologic block motions, and elastic dislocation the-

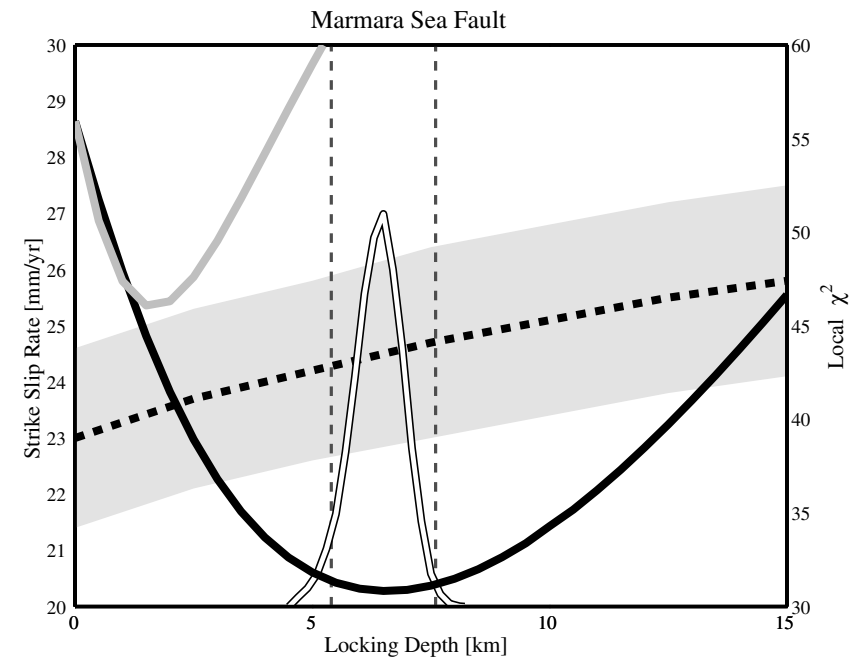

Figure 4. The solid black line shows the local chisquare value as a function of locking depth for the straight fault geometry. The solid gray line shows the local chi-square value as a function of locking depth for the stepped fault geometry. The horizontal dashed black line shows the strike-slip rate on the fault as a function of locking depth for the straight fault geometry. The gray shaded region surrounding this line gives the one-sigma uncertainty estimates. The slip rate is the same, within uncertainties, for all locking depths between 0 and $15 \mathrm{~km}$. The white convex curve shows the normalized distribution of fault locking depths recovered from Monte Carlo simulations. The vertical dashed black lines show the extent of the $95 \%$ confidence interval on the fault locking depth that results from these simulations.

ory. The general agreement between our geodetic slip rate estimates on the NAFZ and estimates based on focal mechanism studies (e.g., Jackson and McKenzie, 1984) is evidence that most geologic displacement occurs along faults. If this were not the case, we would expect to see substantially more motion in the observed velocity field and correspondingly higher geodetic slip rate estimates.

Combining our model results with the historic record of earthquakes, we conclude that the Marmara region is susceptible to major $\left(M_{\mathrm{w}}>7\right)$ earthquakes but that strain is accumulating over a substantially shallower depth interval $(\sim 6.5 \mathrm{~km})$ in the Marmara Sea region than elsewhere $(\sim 17$ $\mathrm{km}$ ) in Turkey. This inference has several implications for seismic hazard assessment. First, because seismic moment depends on the product of fault width (or locking depth), fault length, fault displacement, and shear modulus, decreasing the locking depth by a factor of 2.3 leads to a corresponding decrease in moment, all other factors being constant. Thus, our model would predict a factor of 2.3 less moment release in Marmara than that of Hubert-Ferrari et al. (2000). This inference is consistent with the estimate of Ambraseys and Jackson (2000) that the maximum magnitude historic earthquake near Istanbul is $M_{\mathrm{w}}<7.2$. Second, assuming the same moments and displacements as Ambraseys and Jackson (2000), but a width a factor of 2 smaller, 
our model would lead to rupture lengths a factor of 2 greater for earthquakes beneath the Marmara. This could mean that the entire Marmara segment of the northern NAFZ broke both in 1509 and in 1754-1766, decreasing by a factor of 2 (compared to Ambraseys and Jackson [2000]) the time over which strain has accumulated in this region without being relieved by a major earthquake.

Our study has many similarities in approach to that of Hubert-Ferrari et al. (2000), who concluded on the basis of their models that two events as great or greater than the $M_{\mathrm{w}} 7.4$ İzmit event are likely to occur beneath the Marmara Sea. We reach a somewhat less alarming conclusion about the seismic risk in the Marmara region. Therefore, it is important to understand what differences in assumptions lead to such substantial differences in conclusions. Hubert-Ferrari et al. (2000) used a stepped fault geometry quite similar to ours and used the GPS velocities of Straub et al. (1997) to constrain slip rates on the down-dip extensions of faults that are assumed to be locked to $15-\mathrm{km}$ depth. The slip rate that they inferred for the northern strand of the NAFZ $(24 \mathrm{~mm} /$ yr) was, within errors, equal to ours. The most important difference is that in our inversions, we assume that locking depths in the Marmara region may be shallower than elsewhere because, for example, the crustal extension there may lead to a steeper geotherm (cf., Doser and Kanamori, 1986). Using a range of assumed locking depths, we find that the GPS data strongly prefers a shallower locking depth in this region-as shallow as $1-2 \mathrm{~km}$ for the fault geometry of Hubert-Ferrari et al. (2000). While they recognized that creep on faults to shallower locking depths might satisfy the GPS observations, they believed these models are improbable based on the historical record of large $\left(M_{\mathrm{w}}>7\right)$ earthquakes in 1754 and 1766 in the Marmara region. They argue that these two earthquakes occurred on adjacent fault segments and ruptured essentially the entire stepped fault system. Their assumption, based on the İzmit analogy, that rupture would occur to $15-\mathrm{km}$ depth, leads to their inference that the Marmara Sea region is capable of generating earthquakes in excess of $M_{\mathrm{w}} 7.4$ because of the possibility of a greater rupture length there than at İzmit.

It is impossible to determine reliably the magnitudes or even the locations of these preinstrumental earthquakes that occurred in the eighteenth century. However, Ambraseys and Jackson (2000) placed the 1754 and 1766 earthquakes on the same fault segment southeast of Istanbul and concluded that most of the Marmara segment of the northern NAFZ has not ruptured since 1509.

An alternative approach is to examine the relation between geodetic strain accumulation and seismic moment release in the Imperial Valley of California, a region of combined extension and strike-slip deformation that shares some similarities with the Marmara region. An $M_{\mathrm{w}} 7.1$ earthquake ruptured the Imperial fault in 1940, whereas an $M_{\mathrm{w}} 6.6$ earthquake occurred on the same fault segment in 1979 (Doser and Kanamori, 1986). These events were relatively shallow-the more reliably located 1979 event had a hypocentral depth of $8 \mathrm{~km}$ (Archuleta, 1982), a factor of 2 smaller than the hypocentral depth of the İmit earthquake. Doser and Kanamori (1986) investigated the depth distribution of earthquakes in this region, finding a strong inverse correlation with heat flow, with a peak in the frequency of occurrence of earthquakes in the Imperial Valley at 8-km depth. Interseismic strain in this area is concentrated close to the fault and is adequately modeled assuming a locking depth of $7.5 \mathrm{~km}$ (Bennett et al., 1996). This example illustrates that large earthquakes, such as those in the historical record in the Marmara, could result from rupture of faults with shallow locking depths and that the same fault segment can rupture twice over a time span of a few decades.

The highly localized variation in observed GPS velocities across the Marmara Sea leads us to infer a relatively shallow locking depth for the fault segments there. This inference is based on our calculation of interseismic strain accumulation assuming a simple model, a dislocation within a uniform elastic half-space. Hager et al. (1999) investigated the origin of a similarly localized velocity gradient in the Ventura basin region of the Transverse Range of southern California, where simple dislocation models also suggest locking depths of $5 \mathrm{~km}$ for the thrust faults bounding the basin. However, the $1994 M_{\mathrm{w}} 6.8$ Northridge earthquake ruptured to a depth of $17 \mathrm{~km}$, demonstrating that, in this case, the inference of fault locking depth from a simple dislocation model is incorrect. The explanation of this apparent contradiction is that the Ventura basin is characterized by a thick wedge of low-modulus sediments extending to greater than $15-\mathrm{km}$ depth. Using finite-element models, Hager et al. (1999) showed that if the low shear modulus of the sediments is included, the localized velocity gradient across the basin is compatible with faults locked to $15-\mathrm{km}$ depth. Might a similar model be applied to the Marmara?

We do not think that the effect of low-modulus sediments in the Marmara Sea could be nearly as pronounced as it is for the Ventura basin. The sediments in the Marmara are on the order of $4 \mathrm{~km}$ thick (e.g., Aksu et al., 2000), whereas the Ventura basin sediments are greater than $15 \mathrm{~km}$ thick, one of the thickest piles of Pliocene-Pleistocene sediments in the world. Although further detailed work examining the effects of both horizontal and vertical variations in elastic moduli is in order, we doubt that such work will substantially change our inferences about relative variations in locking depths. Also note that seismic moment depends on the product of shear modulus and locking depth, so our conclusions about expected seismic moment are more robust than our estimate of locking depth alone.

\section{Conclusions}

Our block model is successful in reproducing the observed secular velocities, with reasonable fault slip rates. This suggests that it may be a reasonable description of the present day tectonics of northwestern Turkey. In the Marmara region we reject the stepped fault model proposed by Okay et al. (2000) and used by Hubert-Ferrari et al. (2000) to address seismic potential. We find the straight, through- 
going, fault model of Aksu et al. (2000) fits the GPS data best with a locking depth of 6-7 km. Based on this rather shallow locking depth and the historical record of earthquake activity, we suggest the Marmara faults could generate $M_{\mathrm{w}}<7.2$ earthquakes but the $M_{\mathrm{w}}>7.4$ earthquake scenario proposed by Hubert-Ferrari et al. (2000) is unlikely.

\section{Acknowledgments}

We thank James Savage and Ross Stein for thoughtful comments. This research was supported by NSF grants EAR-9614302, EAR-9909619, INT-9909619, and a Grayce B. Kerr fellowship (BJM).

\section{References}

Aksu, A., T. Calon, and R. Hiscott (2000). Anatomy of the North Anatolian Fault Zone in the Marmara Sea, Western Turkey: extensional basins above a continental transform, GSA Today 10, no. 6, 3-7.

Ambraseys, N. (1970). Some characteristic features of the Anatolian fault zone, Earthquake mechanics, Tectonophysics 9, no. 2-3, 143-165.

Ambraseys, N., and J. Jackson (2000). Seismicity of the Sea of Marmara (Turkey) since 1500, Geophys. J. Int. 141, F1-F6.

Archuleta, R. J. (1982). Hypocenter for the 1979 Imperial Valley earthquake, Geophys. Res. Lett. 9, no. 6, 625-628.

Barka, A. (1999). The 17 August 1999 İzmit earthquake, Science 285, no. $5435,1858-1859$.

Barka, A., and K. Kadinsky-Cade (1988). Strike slip fault geometry in Turkey and its influence on earthquake activity, Tectonics 7, no. 3, 663-684.

Bennett, R., W. Rodi, and R. Reilinger (1996). Global Positioning System constraints on fault slip rates in Southern California and northern Baja, Mexico, J. Geophys. Res. 101, no. 10, 21,943-21,960.

Doser, D., and H. Kanamori (1986). Depth of seismicity in the Imperial Valley region (1977-1983) and its relationship to heat flow, crustal structure, and the October 15, 1979, earthquake, J. Geophys. Res. 91, no. B1, 675-688.

Hager, B., G. Lyzenga, A. Donnellan, and D. Dong (1999). Reconciling rapid strain accumulation with deep seismogenic fault planes in the Ventura Basin, California, J. Geophys. Res. 104, no. 11, 25,20725,219 .

Hubert-Ferrari, A., A. Barka, E. Jacques, S. Nalbant, B. Meyer, R. Armijo, P. Tapponier, and G. King (2000). Seismic hazard in the Marmara Sea region following the 17 August 1999 İzmit earthquake, Nature 404, 269-271.

Jackson, J. A., and D. P. McKenzie (1984). Active tectonics of the Alpine Himalayan Belt between western Turkey and Pakistan, Geophys. J. R. Astr. Soc. 77, 185-246.

Matsu'ura, M., D. D. Jackson, and A. Cheng (1986). Dislocation model for aseismic crustal deformation at Hollister, California, J. Geophys. Res. 91, 12,661-12,674.

McClusky, S., S. Balassanian, A. Barka, C. Demir, S. Ergintav, I. Georgiev, O. Gurkan, M. Hamburger, K. Hurst, H. Kahle, K. Kastens, G. Kekelidze, R. King, V. Kotzev, O. Lenk, S. Mahmoud, A. Mishin, M. Nadariya, A. Ouzounis, D. Paradissis, Y. Peter, M. Prilepin, R. Reilinger, I. Sanli, H. Seeger, A. Tealeb, M. N. Toksoz, and G. Veis (2000). Global positioning system constraints on plate kinematics and dynamics in the eastern Mediterranean and Caucasus, J. Geophys. Res. 105, no. 3, 5695-5719.

McClusky, S. C., S. C. Bjornstad, B. H. Hager, R. W. King, B. J. Meade, M. M. Miller, F. C. Monastero, and B. J. Souter (2001). Present day kinematics of the eastern California Shear Zone from a geodetically constrained block model, Geophys. Res. Lett. 28, no. 17, 3389-3372.

McKenzie, D. (1972). Active tectonics of the Mediterranean region, Geophys. J. R. Astr. Soc. 30, no. 2, 109-185.

Nalbant, S., A. Hubert, and G. King (1998). Stress coupling between earth- quakes in northwest Turkey and the north Aegean Sea, J. Geophys. Res. 103, no. 10, 24,469-24,486.

Okada, Y. (1985). Surface deformation due shear and tensile faults in a half-space, Bull. Seism. Soc. Am. 75, 1135-1154.

Okay, A., A. Kaslilar-Ozcan, C. Imren, A. Boztepe-Guney, E. Demirbag, and I. Kuscu (2000). Active faults and evolving strike-slip basins in the Marmara Sea, Northwest Turkey; a multichannel seismic reflection study, Tectonophysics 321, no. 2, 189-218.

Parsons, T., S. Toda, R. Stein, A. Barka, and J. Dieterich (2000). Heightened odds of large earthquakes near Istanbul: an interaction-based probability calculation, Science $\mathbf{2 8 8}$, no. 5466, 661-665.

Reilinger, R., S. Ergintav, R. Burgmann, S. McClusky, O. Lenk, A. Barka, O. Gurkan, L. Hearn, K. L. Feigl, R. Cakmak, B. Aktug, H. Ozener, and M. N. Toksöz (2000). Coseismic and postseismic fault slip for the 17 August 1999, M = 7.5, İzmit, Turkey Earthquake, Science 289, 1519-1524.

Savage, J., and R. Burford (1973). Geodetic determination of relative plate motion in central California, J. Geophys. Res. 78, no. 5, 832-845.

Savage, J. C., and M. Lisowski (1998). Viscoelastic coupling model of the San Andreas Fault along the Big Bend, Southern California, J. Geophys. Res. 103, no. 4, 7281-7289.

Schindler, C., and M. Pfister (Editors) (1997). Active Tectonics of Northwestern Anatolia: The MARMARA Poly-Project, v/d/f, Zurich, Switzerland.

Souter, B. J. (1998). Comparisons of geological models to GPS observations in southern California, Ph.D. Thesis, Massachusetts Institute of Technology, Cambridge, Massachusetts.

Stein, R., A. Barka, and J. Dieterich (1997). Progressive failure on the North Anatolian Fault since 1939 by earthquake stress triggering, Geophys. J. Int. 128, no. 3, 594-604.

Straub, C., H.-G. Kahle, and C. Schindler (1997). GPS and geologic estimates of tectonic activity in the Marmara Sea region, NW Anatolia, J. Geophys. Res. 102, no. b12, 27,587-27,601.

Toksöz, M. N., R. E. Reilinger, C. G. Doll, A. A. Barka, and N. Yalcin (1999). Izmit (Turkey) earthquake of 17 August 1999: first report, Seism. Res. Lett. 70, no. 6, 669-679.

Toksöz, M. N., A. F. Shakal, and A. I. Michael (1979). Space-time migration of earthquakes along the North Anatolian fault zone and seismic gaps, Pure Appl. Geophys. 117, no. 6, 1258-1270.

Wessel, P., and W. Smith (1991). Free software helps map and display data, EOS 72, no. 41, 445-446.

Department of Earth, Atmospheric \& Planetary Sciences

Massachusetts Institute of Technology

Cambridge, Massachusetts

(B.J.M., B.H.H., S.C.M., R.E.R.)

\section{TUBITAK}

Marmara Research Center

ESRI Gebze 41470, Turkey

(S.E.)

General Command of Mapping Cebece

Ankara, Turkey

(O.L.)

Istanbul Technical University

Eurasia Earth Science Institute Ayazaga

Istanbul, Turkey

(A.B.)

Kandilli Observatory

Bogazici University

Istanbul, Turkey

(H.O.)

Manuscript received 22 September 2000. 